\title{
Traumatic Separation of the Distal Humeral Epiphysis
}

\author{
N. K. Sferopoulos* \\ Department of Pediatric Orthopaedics, "G. Gennimatas" Hospital, Thessaloniki, Greece
}

*Corresponding Author: N. K. Sferopoulos, Department of Pediatric Orthopaedics, "G. Gennimatas" Hospital,Thessaloniki, Greece,Email:sferopoulos@in.gr,sferopoulos@yahoo.com

\begin{abstract}
Traumatic separation of the distal humeral epiphysis with or without a metaphyseal wedge fragment is rarely encountered in the literature before 1978. Once recognized, larger series appeared in the literature, so it is now well documented that it is not such a rare injury, although the initial diagnosis of the lesion is a major problem. A correct diagnosis would only be possible with the aid of arthrography, ultrasound, or magnetic resonance imaging (MRI), especially if there is no significant displacement or in neonates and infants, because the ossification center of the capitellum, which usually appears after the age of 8 months, is not radiographically visible.
\end{abstract}

\section{EDITORIAL}

Most fractures involving the entire distal humeral physis usually occur in neonates, infants and young children before the age of 2 years. The physeal line is transverse and smooth in neonates and infants. It is also quite proximal, so it is cited closely to the centre of the olecranon fossa. A hyperextension injury in this age group is more likely to result in a physeal separation than a bony supracondylar fracture. Before the age of 7 years the distal humeral epiphysis includes the secondary ossification of the medial epicondyle. In older children, only the lateral and medial condylar physeal lines are included. The physeal line progresses more distally, with maturation of the humerus, to form a central ' $\mathrm{V}$ ' between the medial and lateral condylar physes. This V-shaped configuration of the physeal line protects the distal humerus from physeal injuries.

Physeal separations of the distal humerus may be due to birth injuries, child abuse, falls or direct injuries. Birth injuries have occurred after both vaginal and cesarean deliveries. Confirmed or suspected child abuse in infants and young children has also been reported. Traumatic separation of the distal humeral epiphysis may also be due to a fall or direct injury. It has been shown that in young infants a physis is more likely to fail with rotary shear forces than with pure bending or tension forces, which produce other fracture patterns in older children. These fractures are almost always extension-type injuries with the distal epiphyseal fragment posterior to the metaphysis. A rare flexion type of injury may occasionally occur in which the epiphyseal fragment is displaced anteriorly.

Fractures of the entire distal humeral physis are classified into three groups, based on the appearance of the primary ossification centers of the distal humerus. Group A fractures occur in infants up to 12 months of age, before the secondary ossification center of the capitellum appears. They are usually Salter-Harris type I physeal injuries. This injury is often missed, or misdiagnosed as elbow dislocation on radiographs, due to the lack of an ossification center in the capitellum (Fig. 1).

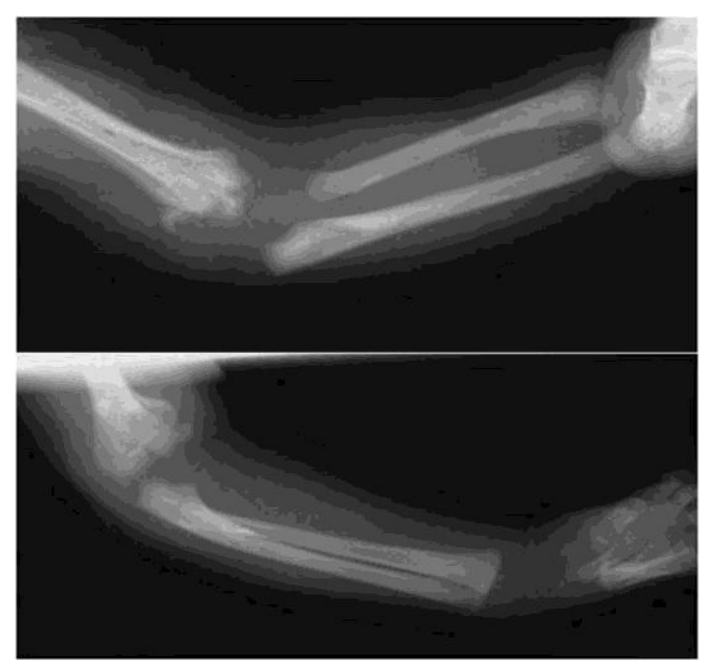

Figure1. This 20-day-old boy had a swollen left elbow after a difficult delivery. The true nature of this injury as a fracture-separation of the entire distal humeral physis was not appreciated until periosteal new bone became visible on both sides of the humerus. 
Group B fractures occur most often in children 12 months to 3 years of age in whom there is definite ossification of the capitellum (Fig. 2).

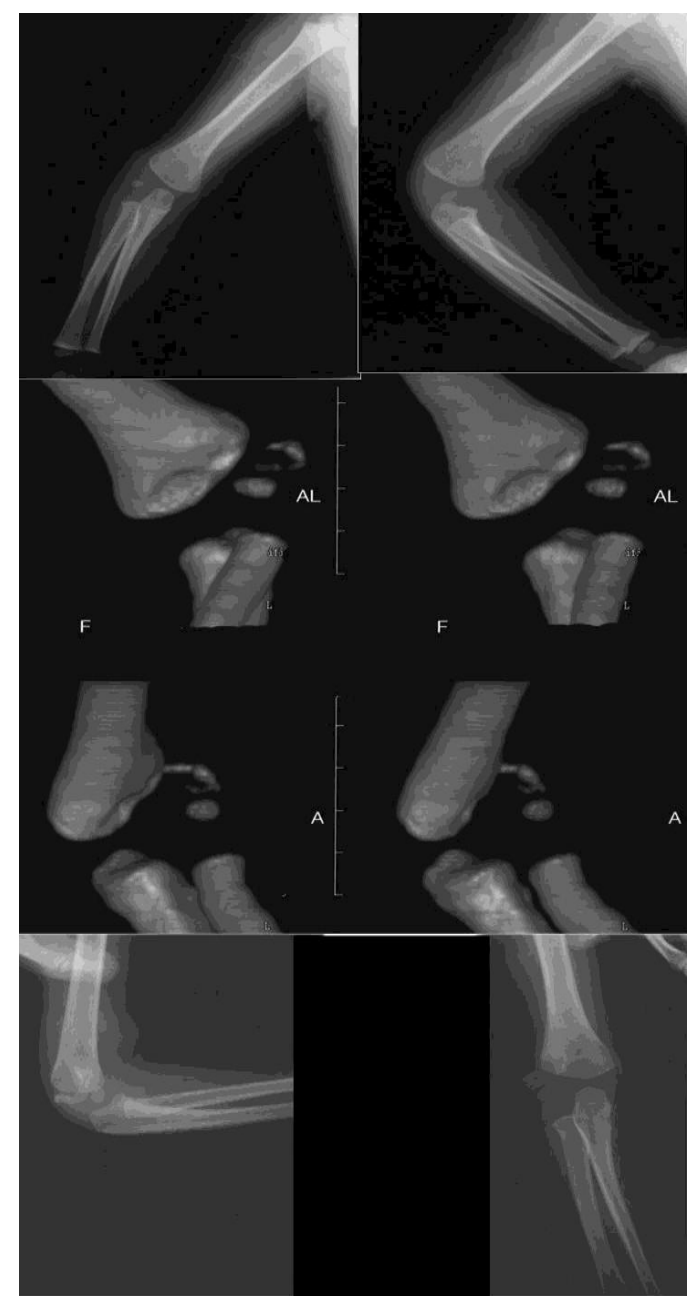

Figure2. A 2-year-old boy with a swollen right elbow after a fall. Initial radiographs indicate a displaced fracture of the distal humerus. The radius and capitellum remain congruent so the diagnosis of a displaced flexion type distal humeral physeal injury was made. Computed tomography 3 weeks later shows anterolateral displacement of the radius and ulna, as well as periosteal callus formation on the lateral side. Radiographs two months post-injury reveal callus formation on the posterolateral aspect of the distal humerus.

There may be a small flake of metaphyseal bone indicating a type II Salter-Harris physeal injury. Group $\mathrm{C}$ fractures occur in older children, from 3 to 7 years of age and result in a large metaphyseal fragment that is most commonly lateral but may also be medial or posterior. They occur before the ossification of trochlea, which usually appears after the age of 7 years. Type $C$ fractures with a large metaphyseal fragment may be confused with either a low supracondylar fracture or with a fracture of the lateral humeral condyle (Fig. 3).

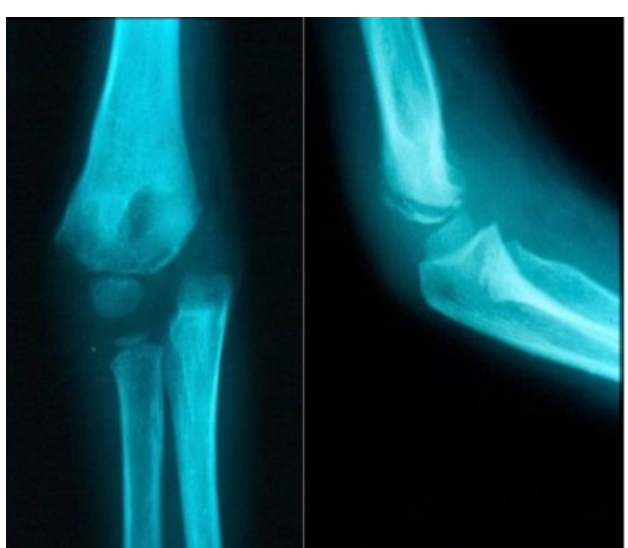

Figure3. A 7-year-old boy with an elbow injury. The radius and capitellum remain congruent, so the diagnosis of a displaced distal humeral physeal injury is made. Note the medial displacement of the proximal radius and ulna and the posteriorly based large metaphyseal (Thurston-Holland) fragment. The patient was treated by closed reduction and cast immobilization.

The clinical appearance includes a painful elbow swelling, decreased movement or disuse and 'muffled' crepitus on movement. In an infant less than 2 years of age with pseudoparalysis and a swollen elbow, secondary to trauma or suspected trauma, a fracture involving the distal humeral physis should always be considered.

Radiographic diagnosis may be difficult, especially if the ossification center of the capitellum is not visible. In this young age group, the proximal radius and ulna maintain an anatomic relationship to each other but are usually displaced posteromedially in relation to the distal humerus, although displacement in any direction may be encountered.

The only secure radiographic relationship that can be determined is that of the primary ossification centers of the distal humerus to the proximal radius and ulna. Once the capitellum ossification centre appears displacement of the entire distal epiphysis is much more obvious. The anatomic relationship of the capitellum ossification centre with the radial head is maintained in fracture-separations of the distal epiphysis of the humerus.

The lesion is usually confused with elbow dislocations, isolated fractures of the lateral condyle, dislocations combined with fractures of the lateral condyle, transcondylar intraarticular fractures and supracondylar fractures of the distal humerus (Fig. 4).

The relationship between the lateral condyle and the proximal radius is disrupted in displaced fractures of the lateral condyle. Elbow 
dislocations have not been reported in birth trauma or in children less than 4 years of age. In elbow dislocations, the displacement of the proximal radius and ulna is almost always posterolateral, and the relationship between the proximal radius and capitellum is also altered. Furthermore, their anatomic relationship is also disrupted in elbow dislocations associated with fractures of the lateral humeral condyle.

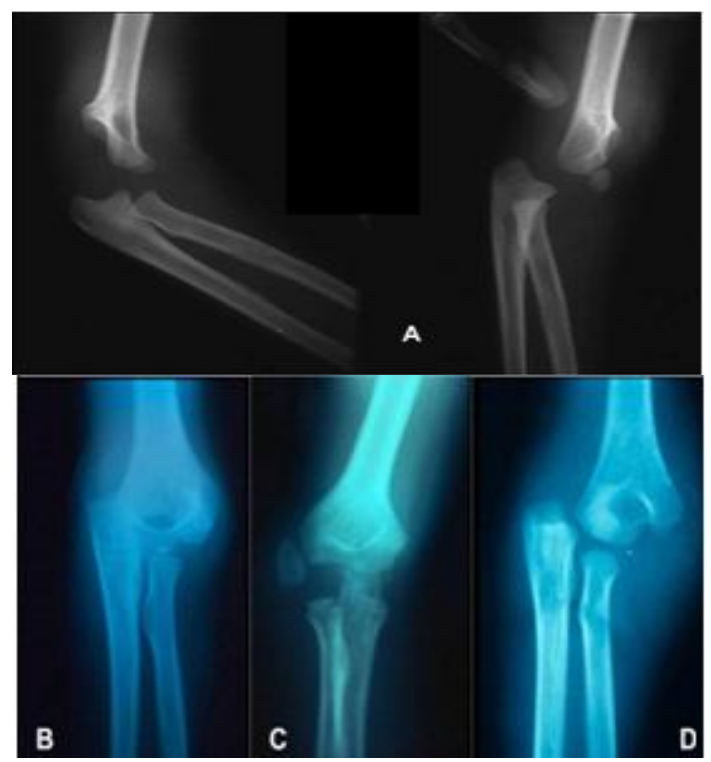

Figure4. Differential diagnosis includes:

A. Elbow dislocation in a 5-year-old boy.

B. Elbow dislocation associated with a displaced fracture of the lateral condyle in a 7-year-old boy.

C. Displaced fracture of the lateral condyle in a 9year-old boy.

In all $A, B$ and $C$ the line drawn through the radius does not transect the capitellar ossification centre.

D. Fracture-separation of the distal humeral epiphysis in a 6-year-old boy. The relationship between the ossification center of the lateral condyle and the proximal radius has been maintained. The marked medial displacement of the distal fragment helps to make the diagnosis.

The correct diagnosis may be supplemented by arthrography and MRI. In neonates and infants ultrasonography may also be used to outline the distal epiphysis of the humerus. Compared with MRI, ultrasound is less expensive, faster and there is no need for sedation. In cases with a missed diagnosis, new periosteal bone forms around the distal humerus, and the whole epiphysis may remain displaced.

Closed reduction, by mild traction, and immobilization is the treatment of choice in early treated cases. Untreated fractures may remodel completely without any residual deformity. Whenever treatment is delayed more than 3 to 5 days, the epiphysis is not freely movable, so reduction should be avoided and the only offered treatment is elbow immobilization in a splint or cast. It is probably better to treat any resulting deformity later with a supracondylar osteotomy rather than risk the complication of physeal injury or osteonecrosis of the epiphysis by performing a delayed closed or open reduction. Only occasionally does an untreated patient have a deformity severe enough to require surgical correction at a later date. Because the articular surface is intact, complete functional recovery is usually expected. The blood supply to the trochlea may be interrupted following an injury through the physis, which may lead to avascular necrosis of the medial humeral condyle. The most common complication is cubitus varus caused by a malunion, osteonecrosis of the medial condyle, or growth arrest. Therefore, early operative fixation with percutaneous pins should be considered in cases with an early diagnosis.

\section{REFERENCES}

[1] Poland J. A practical treatise on traumatic separation of the epiphyses. London: Smith, Elder \& Co., 1898.

[2] Marmor L, Bechtol CO. Fracture separation of the lower humeral epiphysis: report of a case. J Bone Joint Surg Am 1960; 42A: 333-336.

[3] Mayer I, Kolovos D, Loscos R. Epiphysiolysis of the distal humerus in a neborn. Bull Hosp Joint Dis 1967; 28(2): 109-118. PMID: 5583646.

[4] Kaplan SS, Reckling FW. Fracture separation of lower humeral epiphysis with medial displacement. J Bone Joint Surg Am 1971; 53(6): 1105-1108. PMID: 5092800.

[5] Rogers LF, Rockwood CA. Separation of entire distal humeral epiphysis. Radiology 1973; 106(2): 393-399. PMID: 4684483 DOI: 10.1148/106.2.393.

[6] Bright RW, Burstein AH, Elmore SM. Epiphyseal-plate cartilage. A biomechanical and histological analysis of failure modes. J Bone Joint Surg Am 1974; 56(4): 688-703. PMID: 4835816.

[7] Ekengren K, Bergdahl S, Ekström G. Birth injuries to the epiphyseal cartilage. Acta Radiol Diagn (Stockh) 1978; 19(1B): 197-204. PMID: 654945.

[8] Mizuno K, Hirohata K, Kashiwagi D. Fractureseparation of distal humeral epiphysis in young children. J Bone Joint Surg Am 1979; 61(4): 570-573. PMID: 318560. 
[9] Holda ME, Manoli A, LaMont RL. Epiphyseal separation of the distal end of the humerus with medial displacement. J Bone Joint Surg Am 1980; 62(1): 52-57. PMID: 7351416.

[10] DeLee JC, Wilkins KE, Rogers LF, Rockwood CA. Fracture-separation of the distal humeral epiphysis. J Bone Joint Surg Am 1980; 62(1): 46-51. PMID: 7351415.

[11] Berman JM, Weiner DS. Neonatal fractureseparation of the distal humeral chondroepiphysis: a case report. Orthopedics 1980; 3(9): 875-879. PMID: 24822933 DOI: 10.3928/0147-7447-19800901-11.

[12] Peiro A, Mut T, Aracil J, Martos F. Fractureseparation of the lower humeral epiphysis in young children. Acta Orthop Scand 1981; 52(3): 295-298. PMID: 7282322.

[13] Dameron TB Jr. Transverse fractures of distal humerus in children. Instr Course Lect 1981; 30: 224-235. PMID: 7052828.

[14] Ogden, J.A. Skeletal Injury in the Child. Lea \& Febiger, Philadelphia, 1982.

[15] Hansen PE, Barnes DA, Tullos HS. Arthrographic diagnosis of an injury pattern in the distal humerus of an infant. J Pediatr Orthop 1982; 2(5): 569-572. PMID: 7161394.

[16] Downs DM, Wirth CR. Fracture of the distal humeral chondroepiphysis in the neonate. A case report. Clin Orthop Relat Res 1982; 169: 155-158. PMID: 7105572.

[17] McIntyre WM, Wiley JJ, Charette RJ. Fractureseparation of the distal humeral epiphysis. Clin Orthop Relat Res 1984; 188: 98-102. PMID: 6467733.

[18] Barrett WP, Almquist EA, Staheli LT. Fracture separation of the distal humeral physis in the newborn. J Pediatr Orthop 1984; 4(5): 617-619. PMID: 6490887.

[19] Morrissy RT, Wilkins KE. Deformity following distal humeral fracture in childhood. J Bone Joint Surg Am 1984; 66-A: 557-565. PMID: 6707034.

[20] Peterson HA. Physeal fractures. In: Morrey F, Ed. The elbow and its disorders. Philadelphia: W.B Saunders, 1985: 222-236.

[21] Akbarnia BA, Silberstein MJ, Rende RJ, Graviss ER, Luisiri A. Arthrography in the diagnosis of fractures of the distal end of the humerus in infants. J Bone Joint Surg Am 1986; 68(4): 599-602. PMID: 3957985.

[22] Willems B, Stuyck J, Hoogmartens M, Mulier JC, Eggermont E. Fracture-separation of the distal humeral epiphysis. Acta Orthop Belg 1987; 53(1): 109-111. PMID: 3604638.

[23] Ruo GY. Radiographic diagnosis of fractureseparation of the entire distal humeral epiphysis. Clin Radiol 1987; 38(6): 635-637. PMID: 3690967.
[24] Dias JJ, Lamont AC, Jones JM. Ultrasonic diagnosis of neonatal separation of the distal humeral epiphysis. J Bone Joint Surg Br 1988; 70(5): 825-828. PMID: 3056949.

[25] De Jager LT, Hoffman EB. Fracture-separation of the distal humeral epiphysis. J Bone Joint Surg Br 1991; 73(1): 143-146. PMID: 1991750.

[26] Wilkins KE. Fracture and dislocation of the elbow region. In: Beatie JH, ed. Rockwood, Wilkins's and King, fractures in children. Philadelphia: Lippincott Williams \& Wilkins, 1991.

[27] Yoo CI, Suh JT, Suh KT, Kim YJ, Kim HT, Kim YH. Avascular necrosis after fractureseparation of the distal end of the humerus in children. Orthopedics 1992; 15(8): 959-963. PMID: 1508773.

[28] Stricker SJ, Thomson JD, Kelly RA. Coronalplane transcondylar fracture of the humerus in a child. Clin Orthop Relat Res 1993; 294: 308311. PMID: 8358934.

[29] Abe M, Ishizu T, Nagaoka T, Onomura T. Epiphyseal separation of the distal end of the humeral epiphysis: a follow-up note. J Pediatr Orthop 1995; 15(4): 426-434. PMID: 7560028.

[30] Oh CW, Park BC, Ihn JC, Kyung HS. Fracture separation of the distal humeral epiphysis in children younger than three years old. J Pediatr Orthop 2000; 20(2): 173-176. PMID: 10739277.

[31] Staheli LT. Practice of Pediatric Orthopaedics. Lippincott Williams \& Wilkins, Philadelphia, 2001.

[32] Lutz von Laer. Pediatric Fractures and Dislocations. Thieme, Stuttgart, 2001.

[33] Raupp P, Hass D, Lovasz G. Epiphyseal separation of the distal humerus. J Perinat Med 2002; 30: 528-530. PMID: 12530112 DOI: 10.1515/JPM.2002.083.

[34] Herring A. Tachdjian's pediatric orthopaedics. $3^{\text {rd }}$ edition. WB Saunders, Philadelphia, 2002.

[35] Kasser J, Beaty J. Fractures involving the entire distal humeral physis. In: Rockwood and Wilkin's fractures in children. Sixth edition. Philadelphia: Lippincott Williams and Wilkins, 2006: 623-628.

[36] Tudisco C, Mancini F, De Maio F, Ippolito E. Fracture-separation of the distal humeral epiphysis long-term follow-up of five cases. Injury 2006; 37: 843-848. PMID: 16815392 DOI: 10.1016/j.injury.2006.02.018.

[37] Peterson HA. Epiphyseal growth plate fractures. Springer-Verlag, Berlin Heidelberg, 2007.

[38] Hansen M, Weltzien A, Blum J, Botterill NJ, Rommens PM. Complete distal humeral epiphyseal separation indicating a battered child syndrome: A case report. Arch Orthop 
Trauma Surg 2008; 128: 967-972. PMID: 17965868 DOI: 10.1007/s00402-007-0484-7.

[39] Jacobsen S, Hansson G, Nathorst-Westfelt J. Traumatic separation of the distal epiphysis of the humerus sustained at birth. J Bone Joint Surg $\mathrm{Br}$ 2009; 91(6): 797-802. PMID: $19483235 \quad$ DOI: $10.1302 / 0301-$ 620X.91B6.22140.

[40] Sabat D, Maini L, Gautam VK. Neonatal separation of distal humeral epiphysis during caesarean section: a case report. J Orthop Surg (Hong Kong) 2011; 19: 376-378. PMID: 22184176

DOI: $10.1177 / 230949901101900325$.

[41] Fette A, Mayr J. Slipped distal humerus epiphysis in tiny infants easily detected and followed-up by ultrasound. Ultraschall Med 2012; 33(7):E361-3. PMID: 22274908 DOI: $10.1055 / \mathrm{s}-0031-1281660$.

[42] Supakul N, Hicks RA, Caltoum CB, Karmazyn B. Distal humeral epiphyseal separation in young children: an often-missed fractureradiographic signs and ultrasound confirmatory diagnosis. AJR Am J Roentgenol 2015; 204(2): W192-198. PMID: 25615780 DOI: 10.2214/AJR.14.12788.

[43] Ratti C, Guindani N, Riva G, Callegari L, Grassi FA, Murena L. Transphyseal elbow fracture in newborn: review of literature. Musculoskelet Surg 2015; 99 Suppl 1: S99-105. PMID: 25957551 DOI: 10.1007/s12306-0150366-z.

[44] Abzug JM, Ho CA, Ritzman TF, Brighton BK. Transphyseal Fracture of the Distal Humerus. J Am Acad Orthop Surg 2016; 24(2): e39-44. PMID: 26808044 DOI: 10.5435/JAAOS-D-1500297.

[45] Tharakan SJ, Lee RJ, White AM, Lawrence JT. Distal Humeral Epiphyseal Separation in a Newborn. Orthopedics 2016; 39(4): e764-767. PMID: 27158824 DOI: 10.3928/0147744720160503-01.

Citation: N. K. Sferopoulos. Traumatic Separation of the Distal Humeral Epiphysis. ARC Journal of Orthopedics. 2017; 2(1):24-28. doi:dx.doi.org/ 10.20431/2456-0588.0201004.

Copyright: (C) 2017 Authors. This is an open-access article distributed under the terms of the Creative Commons Attribution License, which permits unrestricted use, distribution, and reproduction in any medium, provided the original author and source are credited. 